\title{
Microstructural Characterization of Hardened AISI 4140 using CrN/CSi Coatings
}

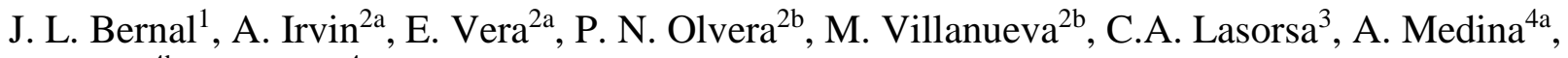 \\ L. Bejar ${ }^{4 b}$, S. Borjas ${ }^{4 c}$ \\ ${ }^{1}$ Mechanics Department, TecNM / Instituto Tecnológico de Orizaba, Orizaba, México. \\ ${ }^{2 a}$ Automotive Mechanics Department, ${ }^{2 b}$ Biotechnology Department, Universidad \\ Politécnica de Pachuca, Hidalgo, México \\ ${ }^{3}$ Mechanics Department, Universidad Tecnológica Nacional, Buenos Aires, Argentina. \\ ${ }^{4 a}$ Instituto de Investigaciones Metalúrgicas, ${ }^{4 b}$ Facultad de Ingeniería Mecánica, ${ }^{4 c}$ Instituto de \\ Física y Matemáticas, UMSNH, Michoacán, México.
}

The design of internal and external layers in coatings is one of the main topics of interest today [1]. On the one hand we look for a material with good properties of tenacity and adhesion and on the other with high hardness and tribological properties when it comes to applications of wear-resistance and corrosion resistance [2-3]. Some investigations had been carried out previously to determine the correlation between the microstructure and the properties of the deposition materials as well as the type of technique chosen [4-6]. In the first part of this study we performed a microstructural characterization of singlephase coatings $\mathrm{CrN} / \mathrm{SiC}$ deposited by PVD tecnique on a steel substrate.

The CrN coatings were produced in a BAI 1200 machine at Oerlikon Balzers in Mexico. They were deposited on 4140 alloy steel substrate with a high vacuum and at a temperature about $450{ }^{\circ} \mathrm{C}$ for 2 hours. Then, $\mathrm{SiC}$ coating were deposited on $\mathrm{CrN}$ layer introducing the precursor hexamethyldisilazane (HMDS) $\mathrm{CH} 3 \mathrm{SiNHSiCH} 3$ and argón as a process gas inside the plasma reactor, at varying pressures of the order of $0.8 \mathrm{~atm}$. The ionization potential fluctuated between $700 \mathrm{~V}$ and $900 \mathrm{~V}$, and the substrate temperature was $600^{\circ} \mathrm{C}$ for the argon process. The film growth rate on average is approx. $1 \mu \mathrm{m} / \mathrm{h}$, and its average hardness is approx. $\sim 9$ on the Mohs scale.

The presence of $\mathrm{SiC}$ and $\mathrm{CrN}$ films on the surface of AISI 4140 steel was confirmed by Scanning Electron Microscopy (SEM), Energy Dispersive Spectroscopy (EDS) and X-Ray Diffraction (XRD) techniques. Figure 1 shows cross sectional SEM micrograph of $\mathrm{CrN}$ and $\mathrm{SiC}$ films as well as EDS maps of $\mathrm{Si}, \mathrm{C}, \mathrm{Cr}$ and $\mathrm{N}$ on AISI 4140 steel. The XRD scans (Figure 2) confirmed the presence of a single phase coatings $\mathrm{SiC}$ and $\mathrm{CrN}$ formed in the AISI 4140 steel. The chemical composition of the sample surface is observed in Figure 3 and it is given in Table 1 confirming the presence of silicon carbide on its surface. These results demonstrate that the process of PVD applied to AISI 4140 steel formed superficial layers $\mathrm{CrN} / \mathrm{SiC}$.

\section{References:}

[1] E. Marin et al, Materials and Design, 89 (2016), p.314-322.

[2] L.A. Dobrzanski, K. Lukaszkowicz, Archives of Materials Science and Engineering, 28 (2007), p. 549-556.

[3] S.A Naghibi, K. Raeissi, M.H. Fahti. Materials Chemistry and Physics, 148 (2014), p. 614-623.

[4] J.R.Frederick, D. Gall, Journal of Applied Physics, 98 (2005), p.1-7

[5] Paul H. Mayrhofer, Christian Mitterer, Lars Hultman, Helmut Clemens, Progress in Materials Science 51 (2006), p. 1032-1114.

[6] J. L. Bernal et al. Microscopy and Microanalysis, 22 (Suppl 3) 2016, p. 1984,1985. 

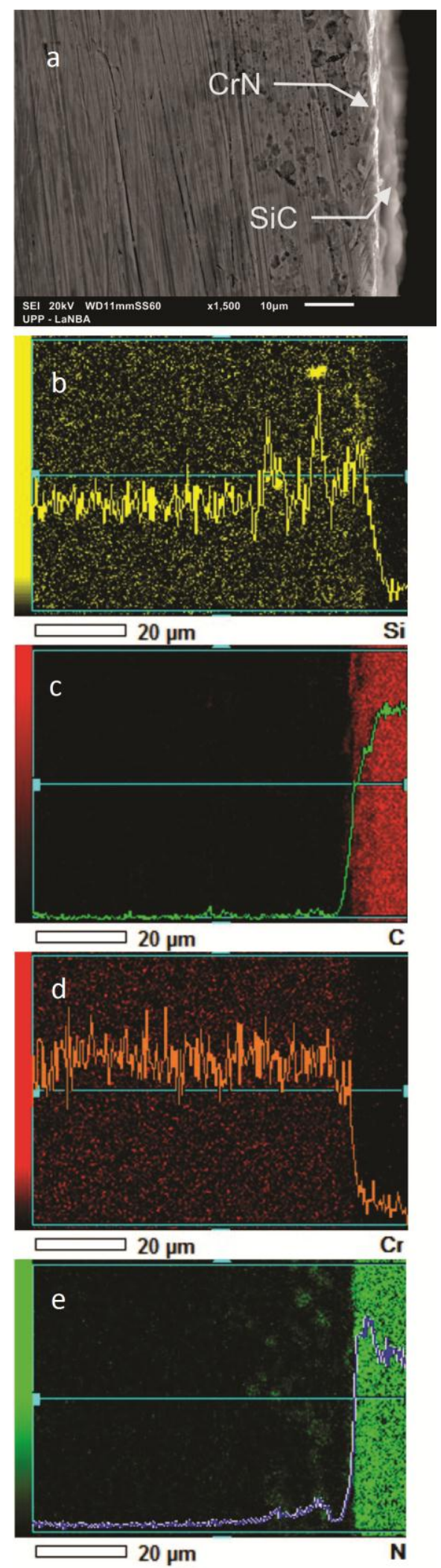

Figure 1. a) cross sectional SEM micrograph and EDS maps of b) Si, c) C, d) Cr, e) N.

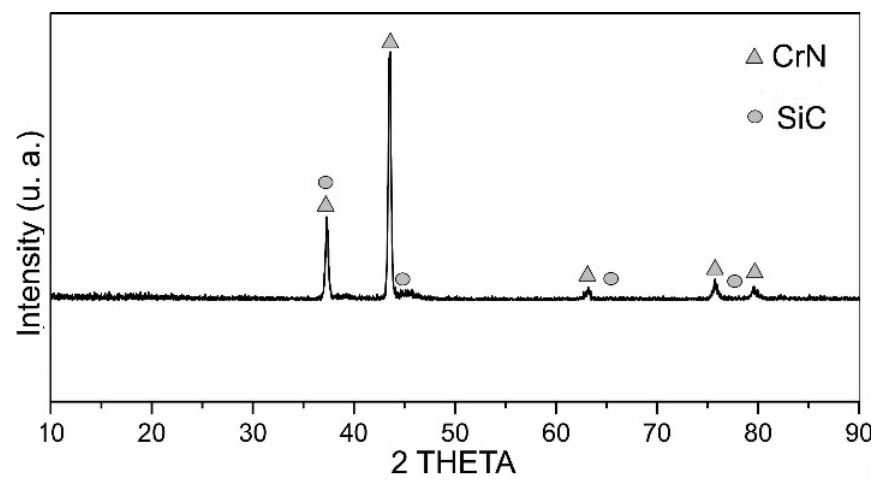

Figure 2. XRD diffraction patterns of $\mathrm{SiC}$ and $\mathrm{CrN}$ coatings.

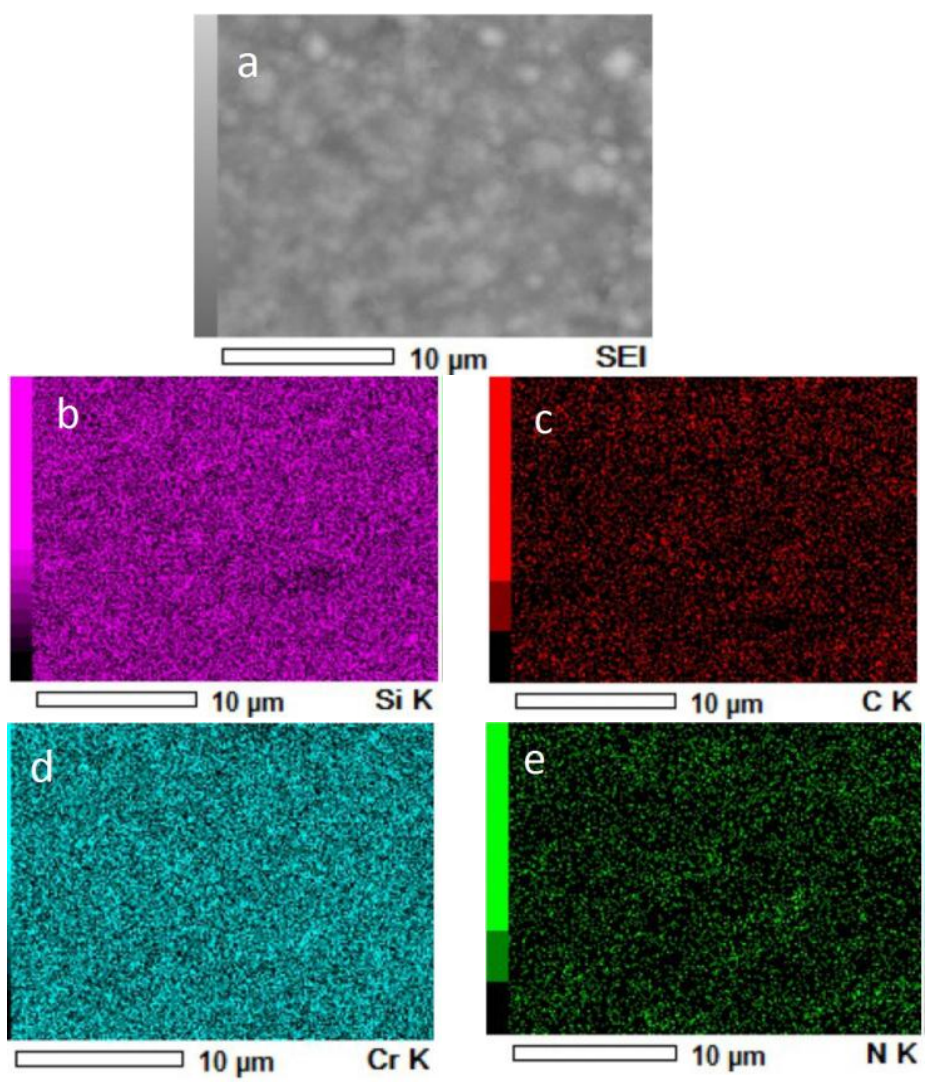

Figure 3. EDS maps of a) sample surface, b) $\mathrm{Si}$, c) $\mathrm{C}, \mathrm{d}) \mathrm{Cr}, \mathrm{e}) \mathrm{N}$.

\begin{tabular}{|c|c|c|c|c|}
\hline Element & $\mathrm{C}$ & $\mathrm{Si}$ & $\mathrm{N}$ & $\mathrm{Cr}$ \\
\hline $\mathrm{Wt} . \%$ & 18.89 & 18.82 & 14.25 & 48.04 \\
\hline
\end{tabular}

Table 1. Chemical composition of the sample surface 